\title{
Claude LIAUZU, Empire du mal contre Grand Satan. Treize siècles de cultures de guerre entre l'islam et l'Occident
}

Paris, Armand Colin, 2005, 356p.

\section{Bruno Michon}

\section{(2) OpenEdition}

\section{Journals}

Édition électronique

URL : http://journals.openedition.org/assr/21611

DOI : 10.4000/assr.21611

ISSN : $1777-5825$

Éditeur

Éditions de l'EHESS

Édition imprimée

Date de publication : 31 décembre 2009

Pagination : 75-342

ISBN : 978-2-7132-2218-4

ISSN : 0335-5985

\section{Référence électronique}

Bruno Michon, «Claude Lıauzu, Empire du mal contre Grand Satan. Treize siècles de cultures de guerre entre l'islam et l'Occident », Archives de sciences sociales des religions [En ligne], 148 | octobredécembre 2009, document 148-83, mis en ligne le 27 janvier 2010, consulté le 21 septembre 2020 URL : http://journals.openedition.org/assr/21611; DOI : https://doi.org/10.4000/assr.21611

Ce document a été généré automatiquement le 21 septembre 2020.

(c) Archives de sciences sociales des religions 


\section{Claude LIAUZU, Empire du mal contre Grand Satan. Treize siècles de cultures de guerre entre l'islam et l'Occident}

Paris, Armand Colin, 2005, 356p.

Bruno Michon

\section{RÉFÉRENCE}

Claude LIAUZu, Empire du mal contre Grand Satan. Treize siècles de cultures de guerre entre l'islam et l'Occident, Paris, Armand Colin, 2005, 356p.

1 Avec Empire du mal contre Grand Satan, Claude Liauzu, nous livre une étude ambitieuse des relations entre l'islam et le christianisme. Pour être plus exact, il cherche à se repérer dans «les atlas mentaux» - terme qu'il reprend à Fernand Braudel - qui résultent depuis des siècles des confrontations entre l'Orient islamique et l'Occident chrétien. C'est bien l'ambition de cet ouvrage que de résumer quatorze siècles d'histoire. L'objectif sous-jacent est toutefois plus qu'historique: C. Liauzu cherche à «déconstruire le discours dominant» et à se positionner contre la théorie du clash des civilisations et contre les tentatives réifiantes de dissoudre l'islam dans une unité mythique. Pour ce faire, l'auteur nous propose un parcours en quatre temps dont chacun aurait pu mériter autant d'ouvrages ad hoc.

2 Dans un premier temps, l'auteur revient sur les effets du 11 septembre 2001. Il montre bien la complexité des réactions à cet évènement et donne à son lecteur les clés de compréhension nécessaires à une appréhension globale des choses. Sa critique envers les théories du complot, florissantes dans le prolongement de ce type de phénomène symboliquement chargé, est particulièrement convaincante et donne les outils historiques nécessaires pour répondre aux arguments bien rodés des partisans du 
complot. Il revient sur les prises de position des différents acteurs de l'intelligentsia mondiale et insiste sur l'apparition des «nouveaux réactionnaires» et du «nouvel antisémitisme» de gauche. Globalement rien de très nouveau mais l'auteur propose un excellent condensé des difficultés que présente la théorie du clash des civilisations.

Le deuxième chapitre est une vaste description des relations islamo-chrétiennes entre le viII ${ }^{e}$ et le $\mathrm{XIX}^{\mathrm{e}}$ siècle. De la chanson de Roland au sort réservé à Mohamed dans La Divine Comédie, C. Liauzu nous rappelle la profondeur historique des préjugés contre les musulmans. Il n'oublie pas de passer de l'autre côté de la Méditerranée et après une courte critique du topos de l'âge d'or de l'Andalousie arabe, il étudie le passage d'une domination musulmane à une domination chrétienne en Méditerranée. Il critique également avec justesse ce qu'il nomme «l'idole des origines», soit la considération normative qu'il suffit d'étudier le Coran pour comprendre l'islam. Dans ce chapitre, l'auteur nous submerge d'exemples qu'il devient difficile d'apprécier. Cas typique ou simple anecdote, le lecteur a du mal à saisir «l'histoire longue» de ces onze siècles.

Le chapitre suivant approfondit la question de la modernité conquérante occidentale en terre d'islam au xix ${ }^{e}$ et au $\mathrm{xx}^{\mathrm{e}}$ siècle. De Jaurès appelant la France à devenir «un grand pays musulman» aux théories orientalistes d'une dégénérescence du monde islamique d'un côté et de la nahda égyptienne aux options radicales kémaliste, C. Liauzu exprime bien la complexité des mouvements d'attirance et de refus de la modernité. Si l'auteur reste toujours dans la nuance, on peut regretter ici la focalisation sur la religion qui risque, malgré tout, de dissocier, comme le montre Olivier Roy dans La Sainte Ignorance, la dimension religieuse et la dimension culturelle de la religion.

Enfin, dans son dernier chapitre, c'est la modernité «désenchantée» qui est au centre des réflexions de l'auteur. Les exemples historiques sont toujours pléthoriques mais l'objectif, critique plus que scientifique, de l'auteur apparaît ici véritablement. On voit difficilement l'intérêt d'affirmer que «les trois religions de la famille d'Abraham ont un rôle capital à jouer dans un sens ou dans l'autre [Armageddon versus œcuménisme]». Le dernier chapitre, centré sur le cas français, n'apporte, de même, rien de très original aux nombreuses recherches menées sur le thème des prédicateurs musulmans, sur la loi sur le port de signes religieux ou sur l'islamophobie des nouveaux réactionnaires.

Pour conclure, l'ouvrage de C.Liauzu fait preuve d'un savoir-faire remarquable en termes de synthèse, la richesse des exemples convoqués et le panorama historique traité permet un bon aperçu de l'histoire mouvementée des relations entre le monde musulman et l'Occident. Cette richesse se fait au détriment de l'approfondissement des exemples et au prix de la superficialité de certaines réflexions. On aurait aimé une analyse approfondie des frontières poreuses entre «l'Orient» et «l'Occident» plutôt que de se contenter d'un trop général occident versus monde musulman. Cet ouvrage constitue néanmoins une somme considérable de connaissances et une référence dans la droite lignée de ceux d'Edward Saïd. 